\title{
Critical iron deficiency anemia with record low hemoglobin: a case report
}

\author{
Audrey L. Chai ${ }^{1 *} \mathbb{D}$, Owen Y. Huang ${ }^{1}$, Rastko Rakočević ${ }^{2}$ and Peter Chung ${ }^{2}$
}

\begin{abstract}
Background: Anemia is a serious global health problem that affects individuals of all ages but particularly women of reproductive age. Iron deficiency anemia is one of the most common causes of anemia seen in women, with menstruation being one of the leading causes. Excessive, prolonged, and irregular uterine bleeding, also known as menometrorrhagia, can lead to severe anemia. In this case report, we present a case of a premenopausal woman with menometrorrhagia leading to severe iron deficiency anemia with record low hemoglobin.

Case presentation: A 42-year-old Hispanic woman with no known past medical history presented with a chief complaint of increasing fatigue and dizziness for 2 weeks. Initial vitals revealed temperature of $36.1^{\circ} \mathrm{C}$, blood pressure $107 / 47 \mathrm{mmHg}$, heart rate 87 beats/minute, respiratory rate 17 breaths/minute, and oxygen saturation 100\% on room air. She was fully alert and oriented without any neurological deficits. Physical examination was otherwise notable for findings typical of anemia, including: marked pallor with pale mucous membranes and conjunctiva, a systolic flow murmur, and koilonychia of her fingernails. Her initial laboratory results showed a critically low hemoglobin of $1.4 \mathrm{~g} /$ $\mathrm{dL}$ and severe iron deficiency. After further diagnostic workup, her profound anemia was likely attributed to a long history of menometrorrhagia, and her remarkably stable presentation was due to impressive, years-long compensation. Over the course of her hospital stay, she received blood transfusions and intravenous iron repletion. Her symptoms of fatigue and dizziness resolved by the end of her hospital course, and she returned to her baseline ambulatory and activity level upon discharge.
\end{abstract}

Conclusions: Critically low hemoglobin levels are typically associated with significant symptoms, physical examination findings, and hemodynamic instability. To our knowledge, this is the lowest recorded hemoglobin in a hemodynamically stable patient not requiring cardiac or supplemental oxygen support.

Keywords: Anemia, Menometrorrhagia, Iron deficiency, Critical care, Transfusion

\section{Background}

Anemia and menometrorrhagia are common and cooccurring conditions in women of premenopausal age $[1,2]$. Analysis of the global anemia burden from 1990 to 2010 revealed that the prevalence of iron deficiency anemia, although declining every year, remained significantly high, affecting almost one in every five women

*Correspondence: achai@usc.edu

${ }^{1}$ Department of Medicine, University of Southern California, Los Angeles, CA, USA

Full list of author information is available at the end of the article
[1]. Menstruation is considered largely responsible for the depletion of body iron stores in premenopausal women, and it has been estimated that the proportion of menstruating women in the USA who have minimalto-absent iron reserves ranges from $20 \%$ to $65 \%$ [3]. Studies have quantified that a premenopausal woman's iron storage levels could be approximately two to three times lower than those in a woman 10 years post-menopause [4]. Excessive and prolonged uterine bleeding that occurs at irregular and frequent intervals (menometrorrhagia) can be seen in almost a quarter of women who are $40-50$ years old [2]. Women with menometrorrhagia original author(s) and the source, provide a link to the Creative Commons licence, and indicate if changes were made. The images or other third party material in this article are included in the article's Creative Commons licence, unless indicated otherwise in a credit line to the material. If material is not included in the article's Creative Commons licence and your intended use is not permitted by statutory regulation or exceeds the permitted use, you will need to obtain permission directly from the copyright holder. To view a copy of this licence, visit http://creativecommons.org/licenses/by/4.0/. The Creative Commons Public Domain Dedication waiver (http://creativeco mmons.org/publicdomain/zero/1.0/) applies to the data made available in this article, unless otherwise stated in a credit line to the data. 
usually bleed more than $80 \mathrm{~mL}$, or 3 ounces, during a menstrual cycle and are therefore at greater risk for developing iron deficiency and iron deficiency anemia. Here, we report an unusual case of a 42-year-old woman with a long history of menometrorrhagia who presented with severe anemia and was found to have a record low hemoglobin level.

\section{Case presentation}

A 42-year-old Hispanic woman with no known past medical history presented to our emergency department with the chief complaint of increasing fatigue and dizziness for 2 weeks and mechanical fall at home on day of presentation.

On physical examination, she was afebrile $\left(36.1{ }^{\circ} \mathrm{C}\right)$, blood pressure was $107 / 47 \mathrm{mmHg}$ with a mean arterial pressure of $69 \mathrm{mmHg}$, heart rate was 87 beats per minute (bpm), respiratory rate was 17 breaths per minute, and oxygen saturation was $100 \%$ on room air. Her height was $143 \mathrm{~cm}$ and weight was $45 \mathrm{~kg}$ (body mass index 22). She was fully alert and oriented to person, place, time, and situation without any neurological deficits and was speaking in clear, full sentences. She had marked pallor with pale mucous membranes and conjunctiva. She had no palpable lymphadenopathy. She was breathing comfortably on room air and displayed no signs of shortness of breath. Her cardiac examination was notable for a grade 2 systolic flow murmur. Her abdominal examination was unremarkable without palpable masses. On musculoskeletal examination, her extremities were thin, and her fingernails demonstrated koilonychia (Fig. 1). She had full strength in lower and upper extremities bilaterally, even though she required assistance with ambulation secondary to weakness and used a wheelchair for mobility for 2 weeks prior to admission. She declined a pelvic examination. No bleeding was noted in any part of her physical examination.

She was admitted directly to the intensive care unit after her hemoglobin was found to be critically low at $1.4 \mathrm{~g} / \mathrm{dL}$ on two consecutive measurements with an unclear etiology of blood loss at the time of presentation. Note that no intravenous fluids were administered prior to obtaining the hemoglobin levels. Upon collecting further history from the patient, she revealed that she has had a lifetime history of extremely heavy menstrual periods: Since menarche at the age of 10 years when her periods started, she has been having irregular menstruation, with periods occurring every $2-3$ weeks, sometimes more often. She bled heavily for the entire 5-7 day duration of her periods; she quantified soaking at least seven heavy flow pads each day with bright red blood as well as large-sized blood clots. Since the age of 30 years, her periods had also become increasingly heavier, with

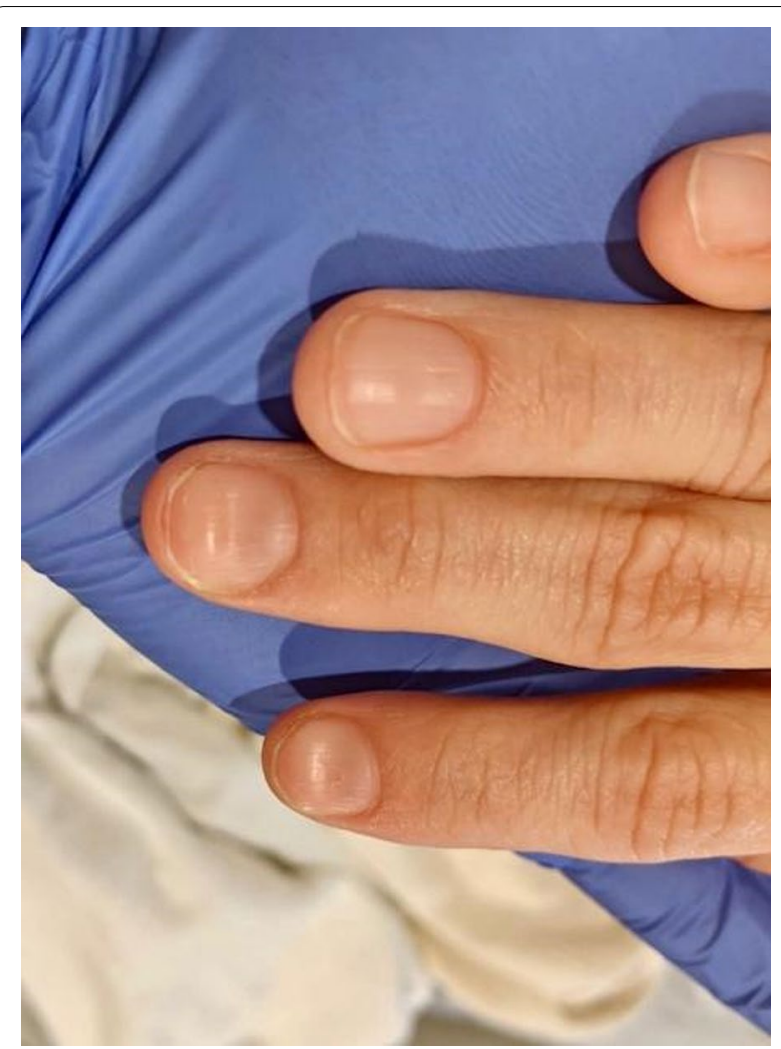

Fig. 1 Koilonychia, as seen in our patient above, is a nail disease commonly seen in hypochromic anemia, especially iron deficiency anemia, and refers to abnormally thin nails that have lost their convexity, becoming flat and sometimes concave in shape

intermittent bleeding in between cycles, stating that lately she bled for "half of the month." She denied any other sources of bleeding.

Initial laboratory data are summarized in Table 1 . Her hemoglobin (Hgb) level was critically low at $1.4 \mathrm{~g} / \mathrm{dL}$ on arrival, with a low mean corpuscular volume (MCV) of $<50.0 \mathrm{fL}$. Hematocrit was also critically low at $5.8 \%$. Red blood cell distribution width (RDW) was elevated to $34.5 \%$, and absolute reticulocyte count was elevated to $31 \times 10^{9} / \mathrm{L}$. Iron panel results were consistent with iron deficiency anemia, showing a low serum iron level of $9 \mu \mathrm{g} / \mathrm{dL}$, elevated total iron-binding capacity (TIBC) of $441 \mu \mathrm{g} / \mathrm{dL}$, low Fe Sat of 2\%, and low ferritin of $4 \mathrm{ng} /$ $\mathrm{mL}$. Vitamin B12, folate, hemolysis labs [lactate dehydrogenase (LDH), haptoglobin, bilirubin], and disseminated intravascular coagulation (DIC) labs [prothrombin time (PT), partial thromboplastin time (PTT), fibrinogen, D-dimer] were all unremarkable. Platelet count was $232,000 / \mathrm{mm}^{3}$. Peripheral smear showed erythrocytes with marked microcytosis, anisocytosis, and hypochromia (Fig. 2). Of note, the patient did have a positive indirect antiglobulin test (IAT); however, she denied any 
Table 1 Summary of the patient's laboratory data

\begin{tabular}{|c|c|c|}
\hline Laboratory & On admission & Reference range \\
\hline WBC & $5400 / \mathrm{mm}^{3}$ & $4500-10,000 / \mathrm{mm}^{3}$ \\
\hline RBC & $1.14 \mathrm{M} / \mathrm{mm}^{3}$ & $3.9-5.1 \mathrm{M} / \mathrm{mm}^{3}$ \\
\hline $\mathrm{Hgb}$ & $1.4 \mathrm{~g} / \mathrm{dL}$ & $12.0-14.6 \mathrm{~g} / \mathrm{dL}$ \\
\hline Hct & $5.8 \%$ & $36.0-44.0 \%$ \\
\hline MCV & $<50.0 \mathrm{fL}$ & $82.0-97.0 \mathrm{fL}$ \\
\hline RDW & $21.9 \%$ & $12-15 \%$ \\
\hline Platelet & $232,000 / \mathrm{mm}^{3}$ & $160,000-360,000 / \mathrm{mm}^{3}$ \\
\hline Retic Pct & $2.7 \%$ & $0.6-2.4 \%$ \\
\hline Abs retic & $31 \times 10^{9} / \mathrm{L}$ & $29-116 \times 10^{9} / \mathrm{L}$ \\
\hline PT & 17.6 seconds & $11.8-14.4$ seconds \\
\hline INR & 1.46 & $0.87-1.13$ \\
\hline PTT & 32.5 seconds & $24.4-36.6$ seconds \\
\hline Fibrinogen & 332 mg/dL & $237-481 \mathrm{mg} / \mathrm{dL}$ \\
\hline D-dimer & $2.16 \mu \mathrm{g} / \mathrm{mL}$ & $\leq 0.49 \mu \mathrm{g} / \mathrm{mL}$ \\
\hline Alk Phos & $150 \mathrm{U} / \mathrm{L}$ & $35-104 \mathrm{U} / \mathrm{L}$ \\
\hline AST & $81 \mathrm{U} / \mathrm{L}$ & $10-35 \mathrm{U} / \mathrm{L}$ \\
\hline ALT & $36 \mathrm{U} / \mathrm{L}$ & $10-35 \mathrm{U} / \mathrm{L}$ \\
\hline Protein total & $5.6 \mathrm{~g} / \mathrm{dL}$ & $6-8 \mathrm{~g} / \mathrm{dL}$ \\
\hline Bili total & $0.5 \mathrm{mg} / \mathrm{dL}$ & $\leq 1.0 \mathrm{mg} / \mathrm{dL}$ \\
\hline Bili direct & $0.3 \mathrm{mg} / \mathrm{dL}$ & $\leq 0.3 \mathrm{mg} / \mathrm{dL}$ \\
\hline Iron & $9 \mu \mathrm{g} / \mathrm{dL}$ & $37-145 \mu \mathrm{g} / \mathrm{dL}$ \\
\hline $\mathrm{TIBC}$ & $441 \mu \mathrm{g} / \mathrm{dL}$ & $250-430 \mu \mathrm{g} / \mathrm{dL}$ \\
\hline Iron sat & $2 \%$ & $15-50 \%$ \\
\hline Ferritin & $4 \mathrm{ng} / \mathrm{mL}$ & $12-263 \mathrm{ng} / \mathrm{mL}$ \\
\hline Haptoglobin & $168 \mathrm{mg} / \mathrm{dL}$ & $30-200 \mathrm{mg} / \mathrm{dL}$ \\
\hline LDH & $206 \mathrm{U} / \mathrm{L}$ & $135-225 \mathrm{U} / \mathrm{L}$ \\
\hline Folate & $12.8 \mathrm{ng} / \mathrm{mL}$ & $\geq 4.6 \mathrm{ng} / \mathrm{mL}$ \\
\hline Vitamin B12 & $1,019 \mathrm{pg} / \mathrm{mL}$ & $232-1245 \mathrm{pg} / \mathrm{mL}$ \\
\hline
\end{tabular}

WBC White Blood Cell Count, RBC Red Blood Cell Count, Hgb Hemoglobin, Hct Hematocrit, MCV Mean Corpuscular Volume, RDW Red Cell Distribution Width, Retic Pct Reticulocyte Percentage, Abs retic Absolute Reticulocyte Count, PT Prothrombin Time, INR International Normalized Ratio, PTT Partial Thromboplastin Time, Alk Phos Alkaline Phosphatase, AST Aspartate transaminase, ALT Alanine Aminotransferase, Bili total Bilirubin total, Bili direct Direct bilirubin, $T I B C$ Total iron binding capacity, $L D H$ Lactate Dehydrogenase

history of pregnancy, prior transfusions, intravenous drug use, or intravenous immunoglobulin (IVIG). Her direct antiglobulin test (DAT) was negative.

A transvaginal ultrasound and endometrial biopsy were offered, but the patient declined. Instead, a computed tomography $(\mathrm{CT})$ abdomen and pelvis with contrast was performed, which showed a $3.5-\mathrm{cm}$ mass protruding into the endometrium, favored to represent an intracavitary submucosal leiomyoma (Fig. 3). Aside from her abnormal uterine bleeding (AUB), the patient was without any other significant personal history, family history, or lab abnormalities to explain her severe anemia.

The patient's presenting symptoms of fatigue and dizziness are common and nonspecific symptoms with a wide range of etiologies. Based on her physical

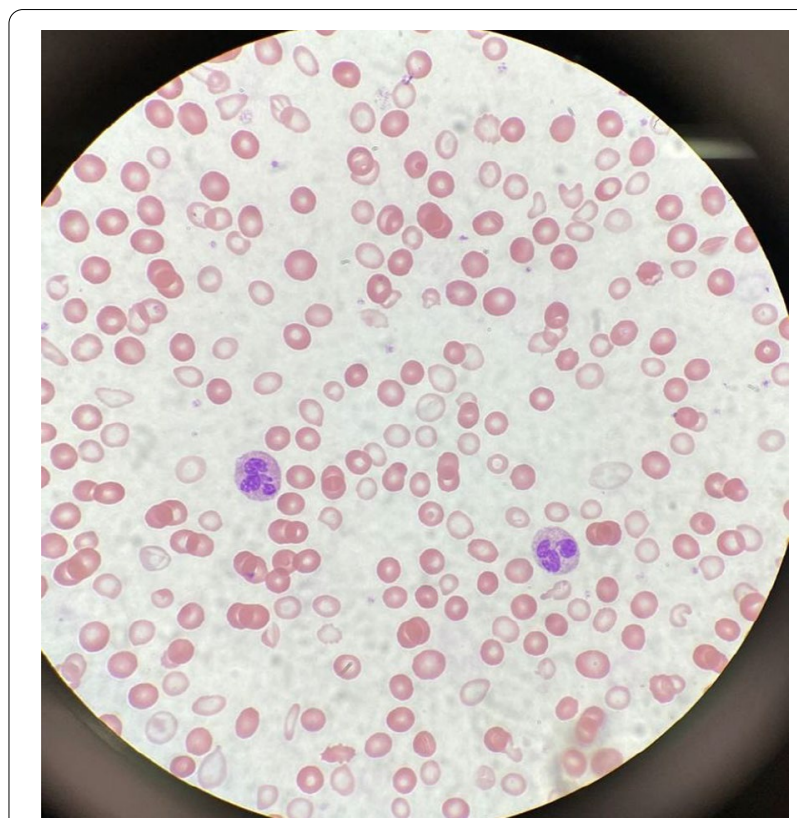

Fig. 2 A peripheral smear from the patient after receiving one packed red blood cell transfusion is shown. Small microcytic red blood cells are seen, many of which are hypochromic and have a large zone of pallor with a thin pink peripheral rim. A few characteristic poikilocytes (small elongated red cells also known as pencil cells) are also seen in addition to normal red blood cells (RBCs) likely from transfusion

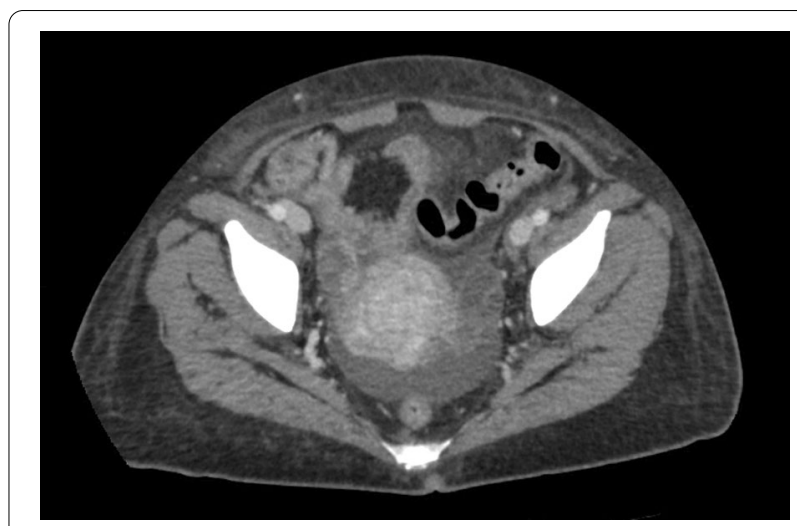

Fig. 3 Computed tomography (CT) of the abdomen and pelvis with contrast was obtained revealing an approximately $3.5 \times 3.0 \mathrm{~cm}$ heterogeneously enhancing mass protruding into the endometrial canal favored to represent an intracavitary submucosal leiomyoma

presentation-overall well-appearing nature with normal vital signs-as well as the duration of her symptoms, we focused our investigation on chronic subacute causes of fatigue and dizziness rather than acute medical causes. We initially considered a range of chronic medical conditions from cardiopulmonary to endocrinologic, 
metabolic, malignancy, rheumatologic, and neurological conditions, especially given her reported history of fall. However, once the patient's lab work revealed a significantly abnormal complete blood count and iron panel, the direction of our workup shifted towards evaluating hematologic causes.

With such a critically low Hgb on presentation (1.4 g/ $\mathrm{dL}$ ), we evaluated for potential sources of blood loss and wanted to first rule out emergent, dangerous causes: the patient's physical examination and reported history did not elicit any concern for traumatic hemorrhage or common gastrointestinal bleeding. She denied recent or current pregnancy. Her CT scan of abdomen and pelvis was unremarkable for any pathology other than a uterine fibroid. The microcytic nature of her anemia pointed away from nutritional deficiencies, and she lacked any other medical comorbidities such as alcohol use disorder, liver disease, or history of substance use. There was also no personal or family history of autoimmune disorders, and the patient denied any history of gastrointestinal or extraintestinal signs and/or symptoms concerning for absorptive disorders such as celiac disease. We also eliminated hemolytic causes of anemia as hemolysis labs were all normal. We considered the possibility of inherited or acquired bleeding disorders, but the patient denied any prior signs or symptoms of bleeding diatheses in her or her family. The patient's reported history of menometrorrhagia led to the likely cause of her significant microcytic anemia as chronic blood loss from menstruation leading to iron deficiency.

Over the course of her 4-day hospital stay, she was transfused 5 units of packed red blood cells and received $2 \mathrm{~g}$ of intravenous iron dextran. Hematology and Gynecology were consulted, and the patient was administered a medroxyprogesterone $(150 \mathrm{mg})$ intramuscular injection on hospital day 2. On hospital day 4, she was discharged home with follow-up plans. Her hemoglobin and hematocrit on discharge were $8.1 \mathrm{~g} / \mathrm{dL}$ and $24.3 \%$, respectively. Her symptoms of fatigue and dizziness had resolved, and she was back to her normal baseline ambulatory and activity level.

\section{Discussion and conclusions}

This patient presented with all the classic signs and symptoms of iron deficiency: anemia, fatigue, pallor, koilonychia, and labs revealing marked iron deficiency, microcytosis, elevated RDW, and low hemoglobin. To the best of our knowledge, this is the lowest recorded hemoglobin in an awake and alert patient breathing ambient air. There have been previous reports describing patients with critically low Hgb levels of $<2 \mathrm{~g} / \mathrm{dL}$ : A case of a 21-year old woman with a history of long-lasting menorrhagia who presented with a $\mathrm{Hgb}$ of $1.7 \mathrm{~g} / \mathrm{dL}$ was reported in 2013 [5]. This woman, although younger than our patient, was more hemodynamically unstable with a heart rate (HR) of 125 beats per minute. Her menorrhagia was also shorter lasting and presumably of larger volume, leading to this hemoglobin level. It is likely that her physiological regulatory mechanisms did not have a chance to fully compensate. A 29-year-old woman with celiac disease and bulimia nervosa was found to have a Hgb of $1.7 \mathrm{~g} / \mathrm{dL}$ : she presented more dramatically with severe fatigue, abdominal pain and inability to stand or ambulate. She had a body mass index (BMI) of 15 along with other vitamin and micronutrient deficiencies, leading to a mixed picture of iron deficiency and non-iron deficiency anemia [6]. Both of these cases were of reproductive-age females; however, our patient was notably older (age difference of $>20$ years) and had a longer period for physiologic adjustment and compensation.

Lower hemoglobin, though in the intraoperative setting, has also been reported in two cases-a patient undergoing cadaveric liver transplantation who suffered massive bleeding with associated hemodilution leading to a $\mathrm{Hgb}$ of $0.6 \mathrm{~g} / \mathrm{dL}$ [7] and a patient with hemorrhagic shock and extreme hemodilution secondary to multiple stab wounds leading to a $\mathrm{Hgb}$ of $0.7 \mathrm{~g} / \mathrm{dL}$ [8]. Both patients were hemodynamically unstable requiring inotropic and vasopressor support, had higher preoperative hemoglobin, and were resuscitated with large volumes of colloids and crystalloids leading to significant hemodilution. Both were intubated and received $100 \%$ supplemental oxygen, increasing both hemoglobin-bound and dissolved oxygen. Furthermore, it should be emphasized that the deep anesthesia and decreased body temperature in both these patients minimized oxygen consumption and increased the available oxygen in arterial blood [9].

Our case is remarkably unique with the lowest recorded hemoglobin not requiring cardiac or supplemental oxygen support. The patient was hemodynamically stable with a critically low hemoglobin likely due to chronic, decades-long iron deficiency anemia of blood loss. Confirmatory workup in the outpatient setting is ongoing. The degree of compensation our patient had undergone is impressive as she reported living a very active lifestyle prior to the onset of her symptoms ( 2 weeks prior to presentation), she routinely biked to work every day, and maintained a high level of daily physical activity without issue.

In addition, while the first priority during our patient's hospital stay was treating her severe anemia, her education became an equally important component of her treatment plan. Our institution is the county hospital for the most populous county in the USA and serves as a safety-net hospital for many vulnerable populations, most of whom have low health literacy and a lack of awareness 
of when to seek care. This patient had been experiencing irregular menstrual periods for more than three decades and never sought care for her heavy bleeding. She, in fact, had not seen a primary care doctor for many years nor visited a gynecologist before. We emphasized the importance of close follow-up, self-monitoring of her symptoms, and risks with continued heavy bleeding. It is important to note that, despite the compensatory mechanisms, complications of chronic anemia left untreated are not minor and can negatively impact cardiovascular function, cause worsening of chronic conditions, and eventually lead to the development of multiorgan failure and even death $[10,11]$.

\section{Acknowledgements}

Not applicable.

\section{Authors' contributions}

$\mathrm{AC}, \mathrm{OH}, \mathrm{RR}$, and PC managed the presented case. AC performed the literature search. $\mathrm{AC}, \mathrm{OH}$, and $\mathrm{RR}$ collected all data and images. $\mathrm{AC}$ and $\mathrm{OH}$ drafted the article. RR and PC provided critical revision of the article. All authors read and approved the final manuscript.

\section{Funding}

No funding to be declared.

\section{Availability of data and materials}

All data generated or analyzed during this study are included in this published article.

\section{Declarations}

Ethics approval and consent to participate

Not applicable.

\section{Consent for publication}

Written informed consent was obtained from the patient for publication of this case report and any accompanying images. A copy of the written consent is available for review by the Editor-in-Chief of this journal.

\section{Competing interests}

The authors declare that they have no competing interests.

\section{Author details}

'Department of Medicine, University of Southern California, Los Angeles, CA USA. ${ }^{2}$ Division of Pulmonary, Critical Care and Sleep Medicine, Department of Medicine, University of Southern California, Los Angeles, CA, USA.

Received: 25 March 2021 Accepted: 21 July 2021

Published online: 13 September 2021

\section{References}

1. Kassebaum NJ. The global burden of anemia. Hematol Oncol Clin. 2016;30(2):247-308.

2. Donnez J. Menometrorrhagia during the premenopause: an overview. Gynecol Endocrinol. 2011;27(sup1):1114-9.

3. Cook JD, Skikne BS, Lynch SR, Reusser ME. Estimates of iron sufficiency in the US population. Blood. 1986;68(3):726-31.

4. Palacios S. The management of iron deficiency in menometrorrhagia. Gynecol Endocrinol. 2011;27(sup 1):1126-30.

5. Can Ç, Gulactı U, Kurtoglu E. An extremely low hemoglobin level due to menorrhagia and iron deficiency anemia in a patient with mental retardation. Int Med J. 2013;20(6):735-6.

6. Jost PJ, Stengel SM, Huber W, Sarbia M, Peschel C, Duyster J. Very severe iron-deficiency anemia in a patient with celiac disease and bulimia nervosa: a case report. Int J Hematol. 2005;82(4):310-1.

7. Kariya T, Ito N, Kitamura T, Yamada Y. Recovery from extreme hemodilution (hemoglobin level of $0.6 \mathrm{~g} / \mathrm{dL}$ ) in cadaveric liver transplantation. A A Case Rep. 2015;4(10):132.

8. Dai J, Tu W, Yang Z, Lin R. Intraoperative management of extreme hemodilution in a patient with a severed axillary artery. Anesth Analg. 2010;111(5):1204-6.

9. Koehntop DE, Belani KG. Acute severe hemodilution to a hemoglobin of $1.3 \mathrm{~g} / \mathrm{dl}$ tolerated in the presence of mild hypothermia. J Am Soc Anesthesiol. 1999;90(6):1798-9.

10. Georgieva Z, Georgieva M. Compensatory and adaptive changes in microcirculation and left ventricular function of patients with chronic iron-deficiency anaemia. Clin Hemorheol Microcirc. 1997;17(1):21-30.

11. Lanier JB, Park JJ, Callahan RC. Anemia in older adults. Am Fam Phys. 2018;98(7):437-42.

\section{Publisher's Note}

Springer Nature remains neutral with regard to jurisdictional claims in published maps and institutional affiliations.

\footnotetext{
Ready to submit your research? Choose BMC and benefit from:

- fast, convenient online submission

- thorough peer review by experienced researchers in your field

- rapid publication on acceptance

- support for research data, including large and complex data types

- gold Open Access which fosters wider collaboration and increased citations

- maximum visibility for your research: over 100M website views per year

At BMC, research is always in progress.

Learn more biomedcentral.com/submissions 